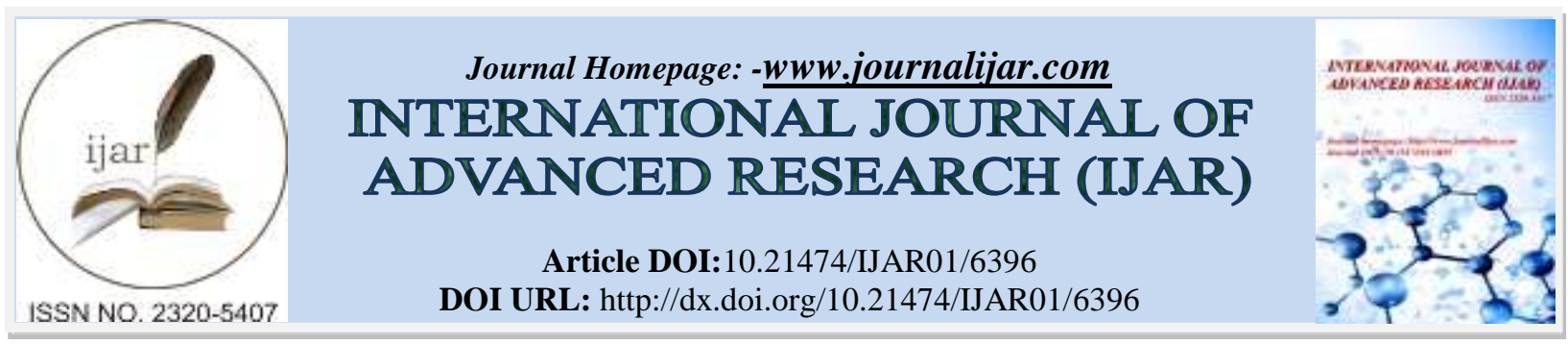

RESEARCH ARTICLE

\title{
CYTOLOGICAL DIAGNOSIS OF EXTRA THYROIDAL MALIGNANCY IN THYROID-A REPORT OF TWO CASES.
}

\section{Dr. K. Kokila ${ }^{1}$. Dr. Vijaya baskar ${ }^{2}$, Dr. Geetha Devadas ${ }^{3}$ and Dr. Bharathi Vidhya Jayanthi ${ }^{4}$.}

1. Post graduate in pathology, Madras Medical College.

2. Assistant professor of pathology, Madras Medical College.

3. Professor of pathology, Madras Medical College.

4. Director \& Professor of pathology, Madras Medical College.

\section{Manuscript Info}

(........................

Manuscript History

Received: 24 November 2017

Final Accepted: 26 December 2017

Published: January 2018

\section{Abstract}

Intra thyroidal metastasis and direct extension of extra thyroidal malignancies can present with clinically palpable nodules and as suspicious nodules on radiological imaging. Metastasis to thyroid is rare and usually discovered during an autopsy especially in individuals with widespread dissemination of the tumor. In autopsy series, the incidence of thyroid metastasis ranges from $0.5 \%$ to $24 \%{ }^{(1)}$ but is much lower in clinical studies. Most common primary tumors that can metastasize to thyroid include carcinoma of kidney, breast, pancreas, colon, ovary, lung, bladder and malignant melanoma ${ }^{(2)}$. It is rare for these tumors to present initially as isolated thyroid nodule or disturbances in thyroid function and is seen in less than a quarter of cases $^{(3)}$.

We reported two cases of extra thyroidal malignancies which were diagnosed by fine needle aspiration cytology. The first case was an invasive breast carcinoma that metastasized to thyroid and another case was direct extension of squamous cell carcinoma of hypopharynx to thyroid.

Primary squamous cell carcinoma of the thyroid is rare and its incidence ranges from $0.2-1.1 \%$ of all thyroid malignancies (4). Whenever malignant squamous cells are seen admixed with thyroid follicular epithelial cells, the possibility of metastasis from occult primary should always be considered while interpreting thyroid cytology. Squamous cell carcinomas metastasizing to the thyroid largely have their origin in the esophagus, lung and head \& neck region.

Invasive breast carcinoma is the most common type of breast cancer which constitutes $85 \%$ of all invasive carcinomas. Breast carcinoma usually metastasizes to lungs, liver, bones and brain. Solitary thyroid metastasis of invasive breast carcinoma is rare.

Copy Right, IJAR, 2018,. All rights reserved. 


\section{Introduction:-}

\section{Case-1:-}

A 60 year old female patient presented with swelling in front of neck for 3 months and swelling in right breast for 6 months. Patient had sudden increase in the size of thyroid swelling. On examination, there was asymmetrical enlargement of the thyroid and was firm in consistency. A swelling of size $4 \times 3 \mathrm{~cm}$ was noted in the upper outer quadrant of right breast. Fine needle aspiration was done in both the swellings and hemorrhagic aspirate was obtained. The breast swelling was reported as ductal carcinoma and thyroid swelling was reported as metastatic carcinomatous deposits from breast. Core needle biopsy was performed in the breast and reported as invasive breast carcinoma.

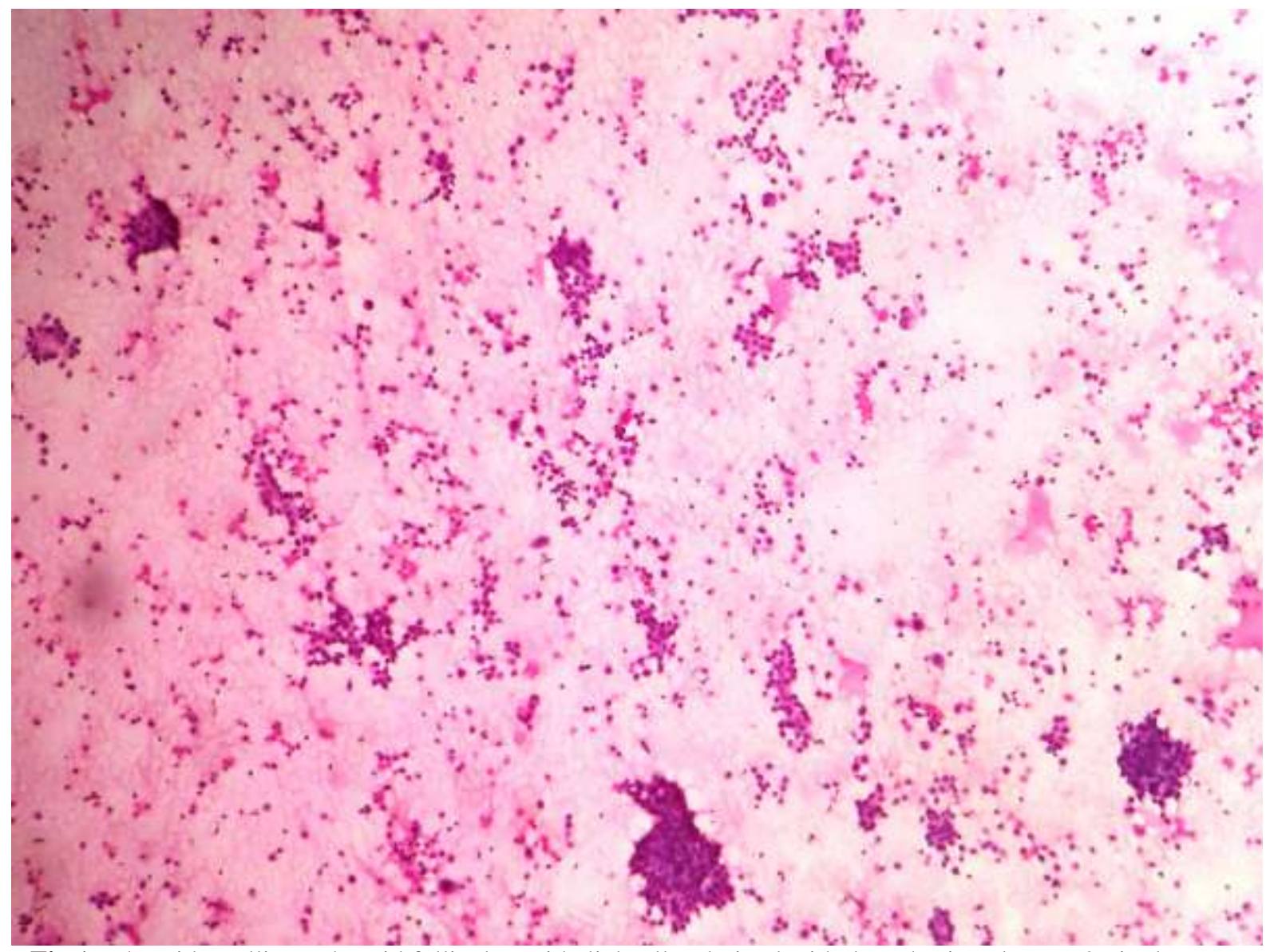

Fig 1:-Thyroid swelling- Thyroid follicular epithelial cells admixed with dyscohesive clusters \& singly scattered malignant duct epithelial cells-H\&E (100X). 


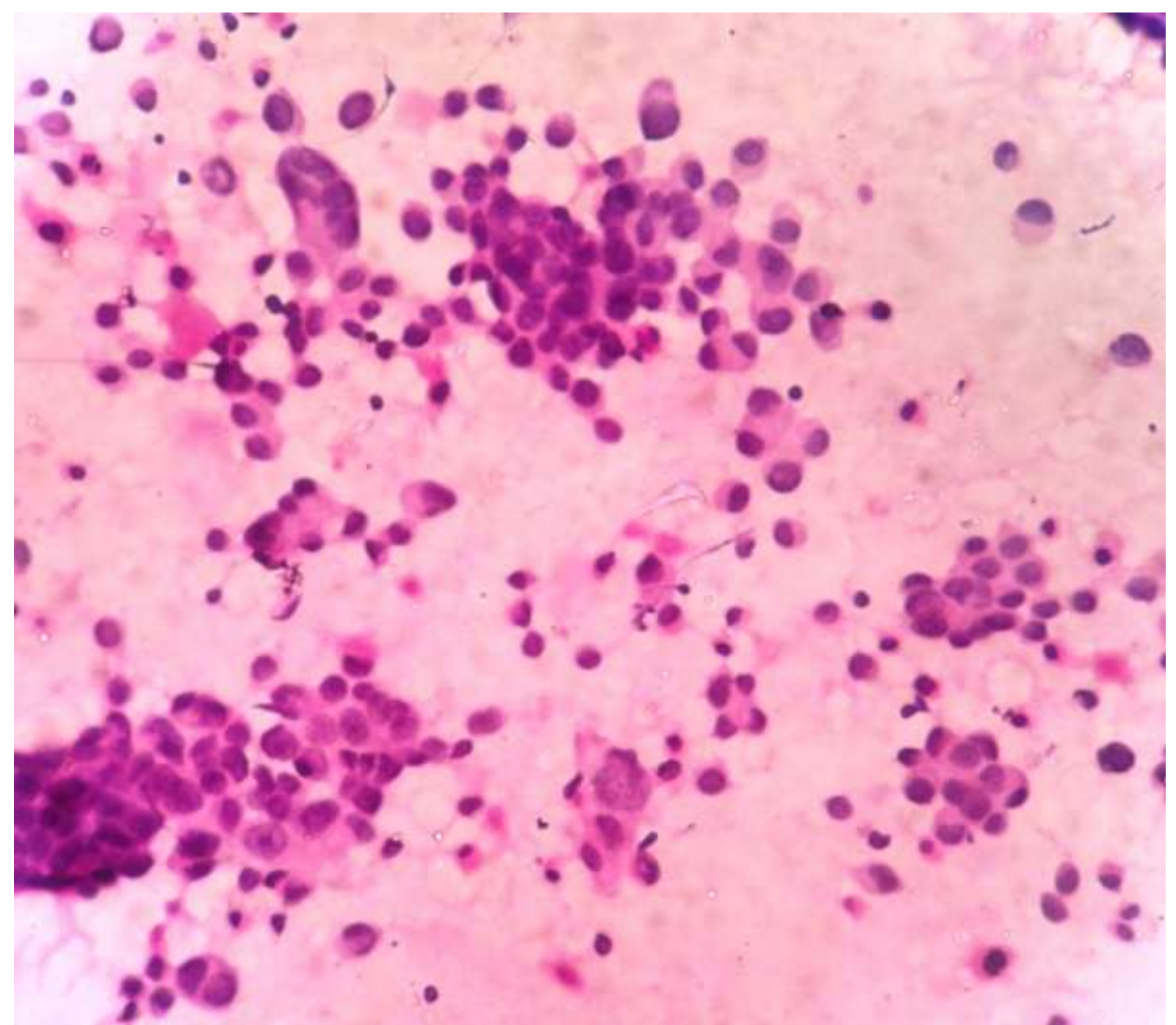

Fig 2:-Thyroid swelling showing malignant ductal epithelial cells which are singly scattered and in clusters- $\mathrm{H} \& \mathrm{E}$ (400X). 


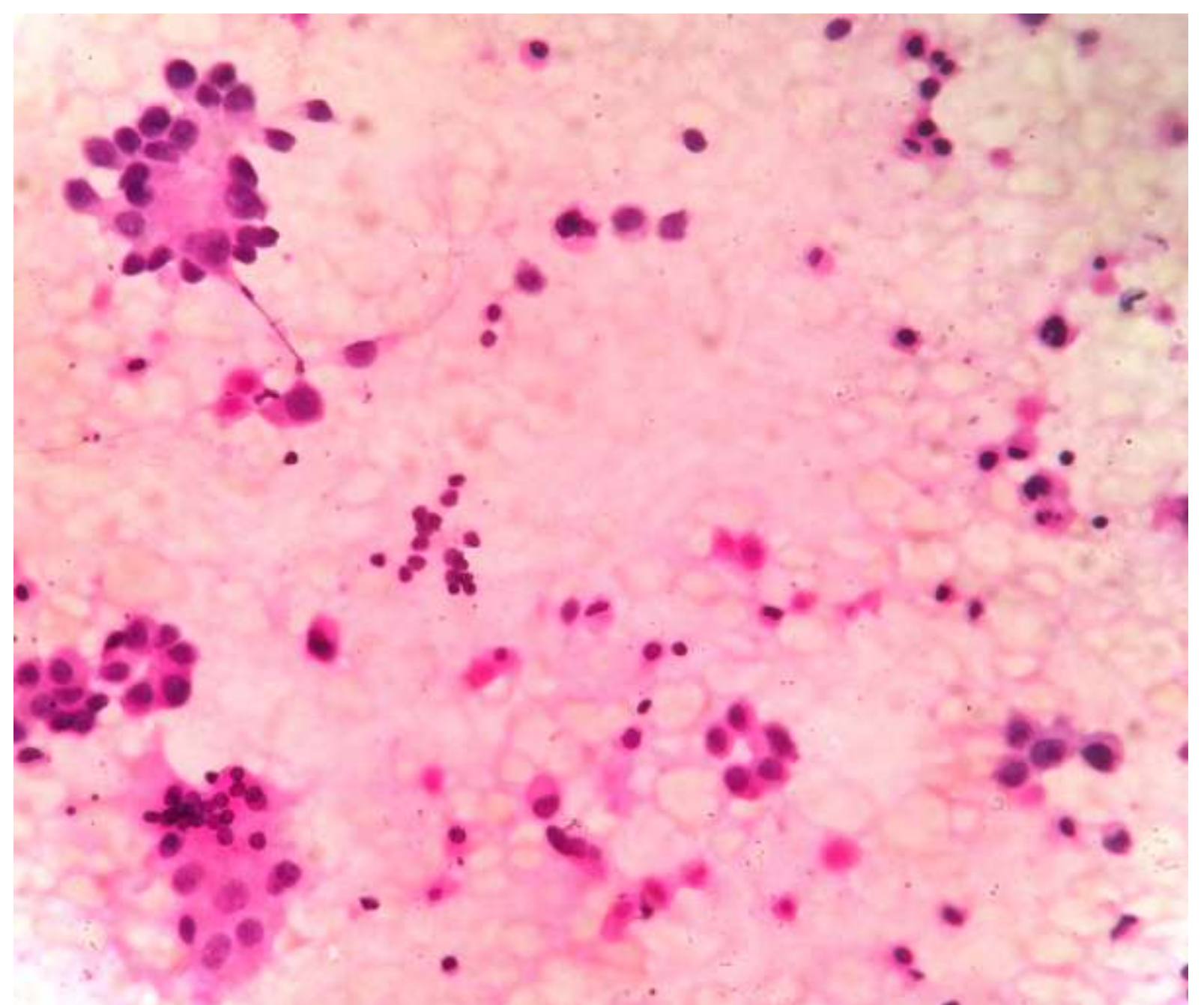

Fig 3:-Thyroid swelling aspirate showing thyroid follicles admixed with malignant ductal epithelial cells- H \& E (400X). 


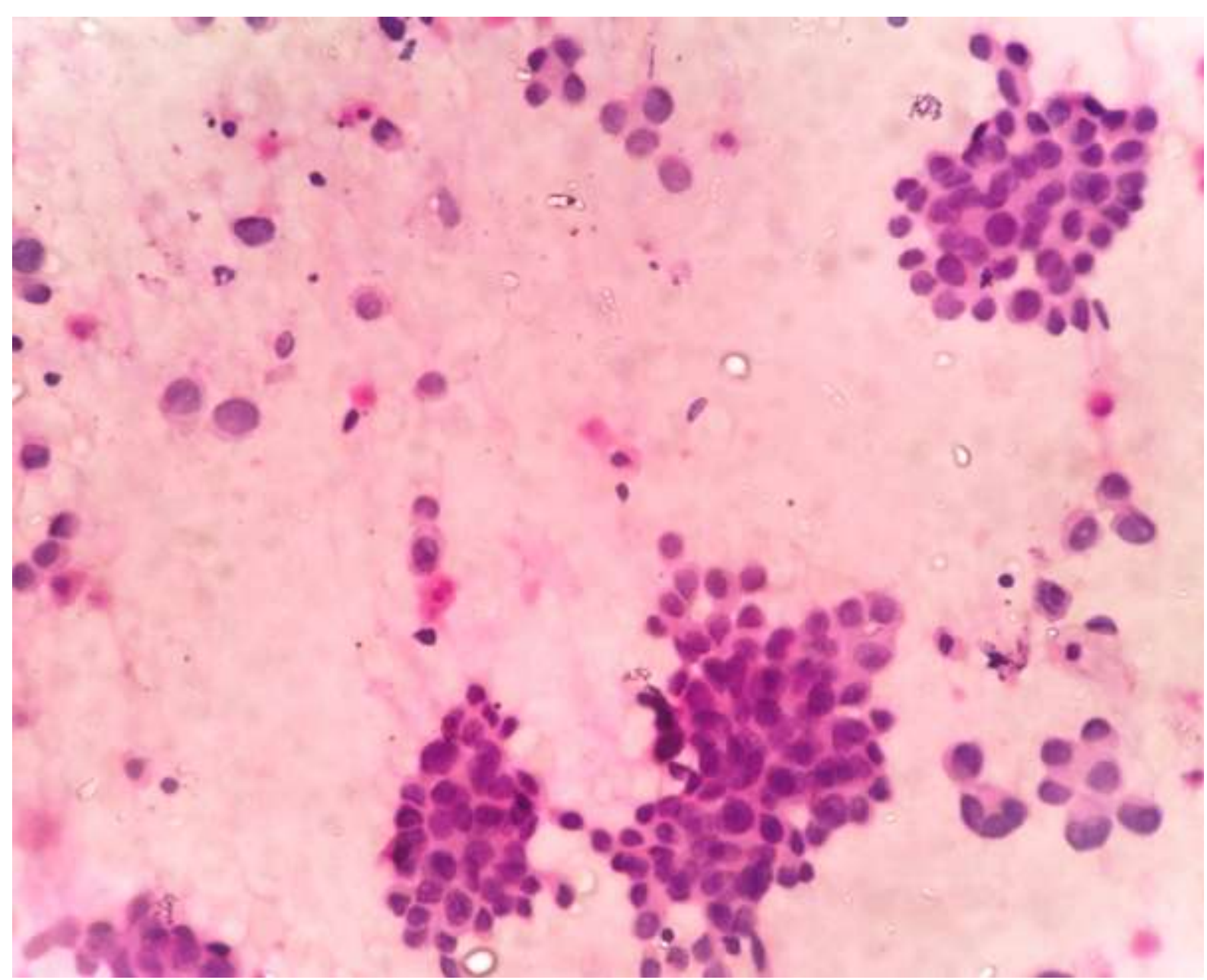

Fig 4:-Right breast swelling showing dyscohesive clusters and singly scattered malignant epithelial cells-H \& E (400X).

\section{Case-2:-}

A 40 year old female patient presented with dysphagia for 6 months with history of voice change. On examination, there was asymmetrical enlargement of the thyroid which was firm in consistency. Imaging showed a hypopharyngeal growth with lateral extension to adjacent structures. Fine needle aspiration was done from the thyroid swelling and hemorrhagic aspirate was obtained. Microscopy revealed features of squamous cell carcinoma extending into thyroid. Later biopsy was performed from the hypopharyngeal growth and reported as infiltrating squamous cell carcinoma with moderate differentiation. 


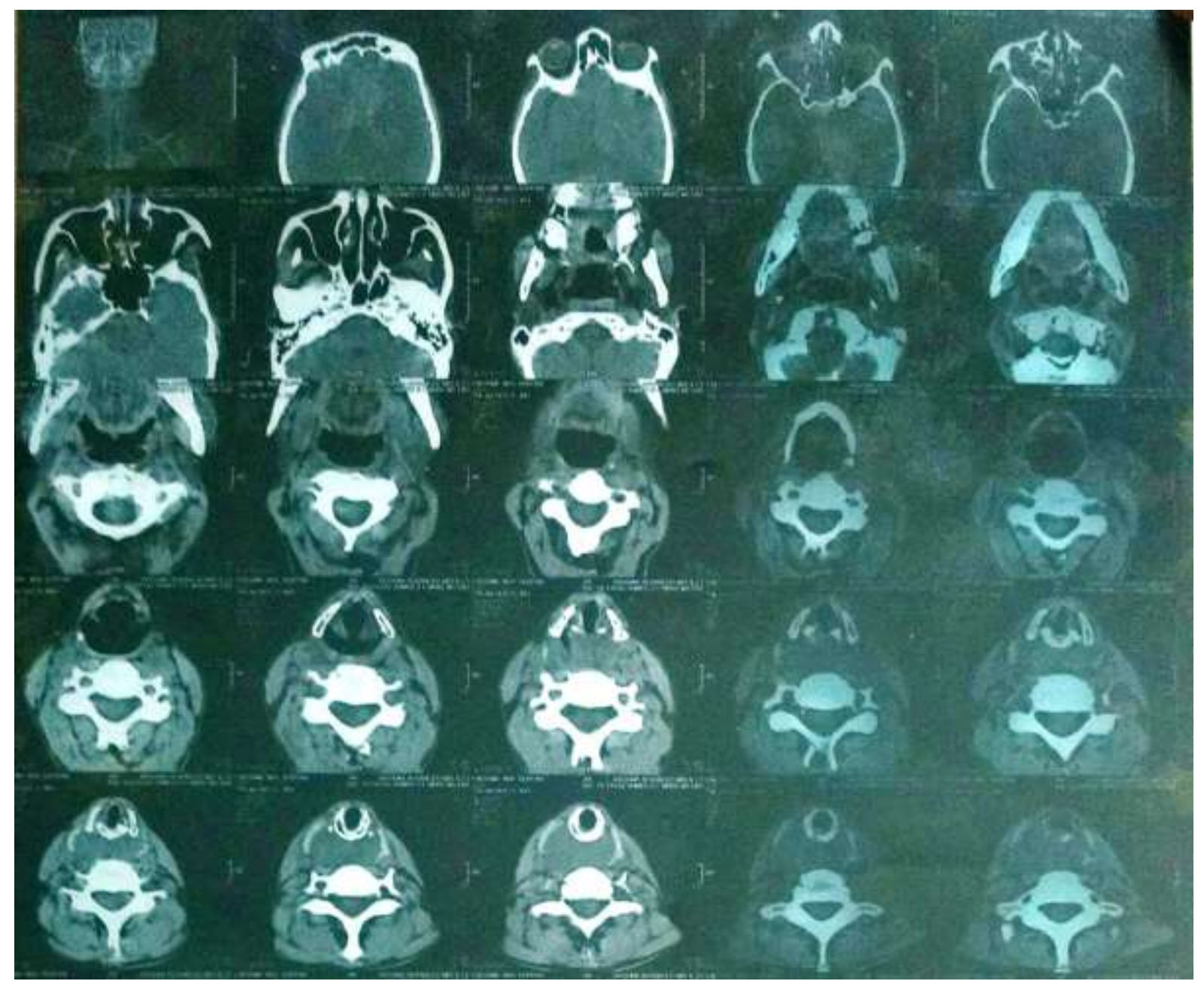

Fig 5:-CT neck showing hypopharyngeal growth 


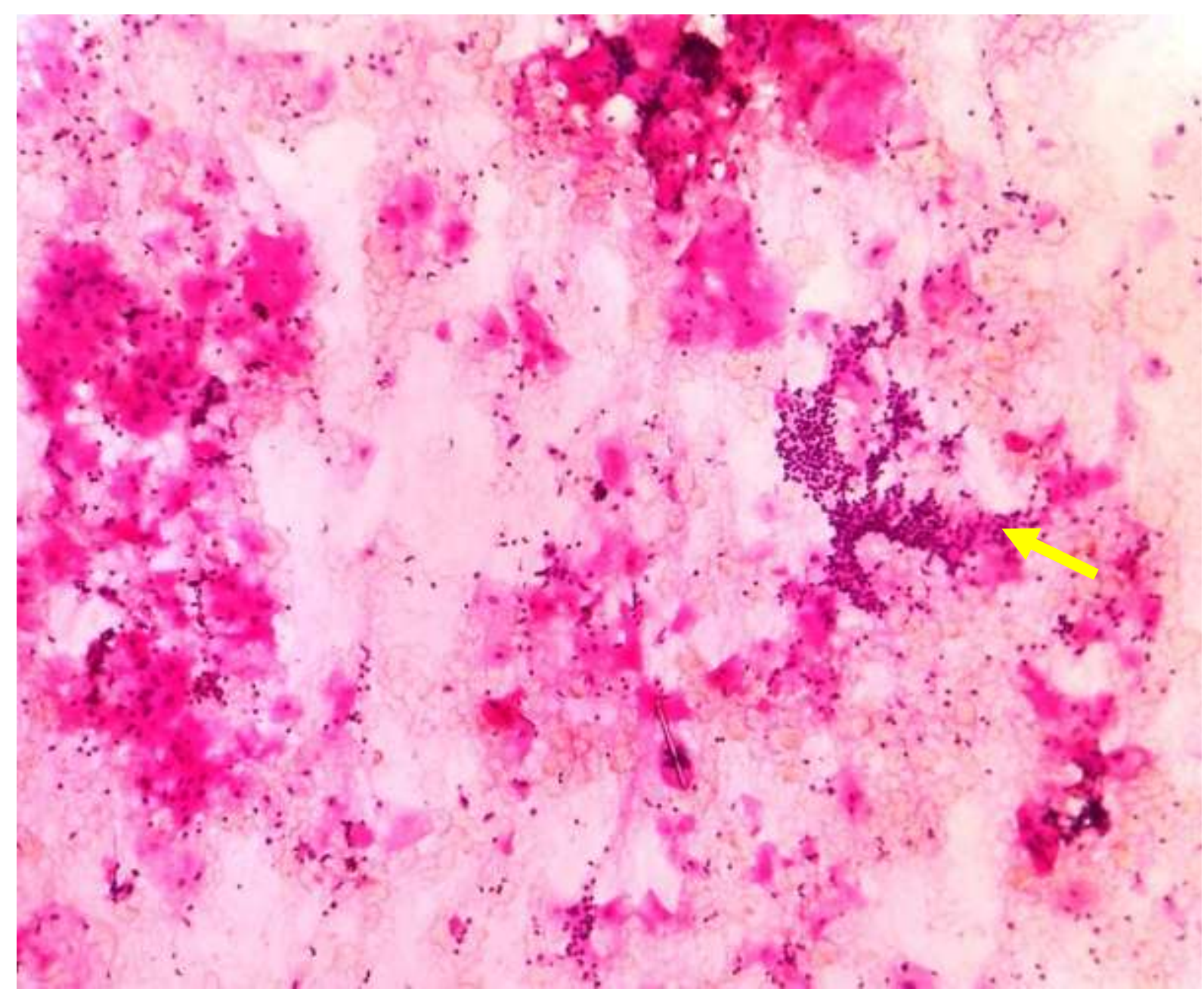

Fig 6:-Monolayered sheets of thyroid follicular epithelial cells (yellow arrow) admixed with malignant squamous epithelial cells- H \& E (100 X) 


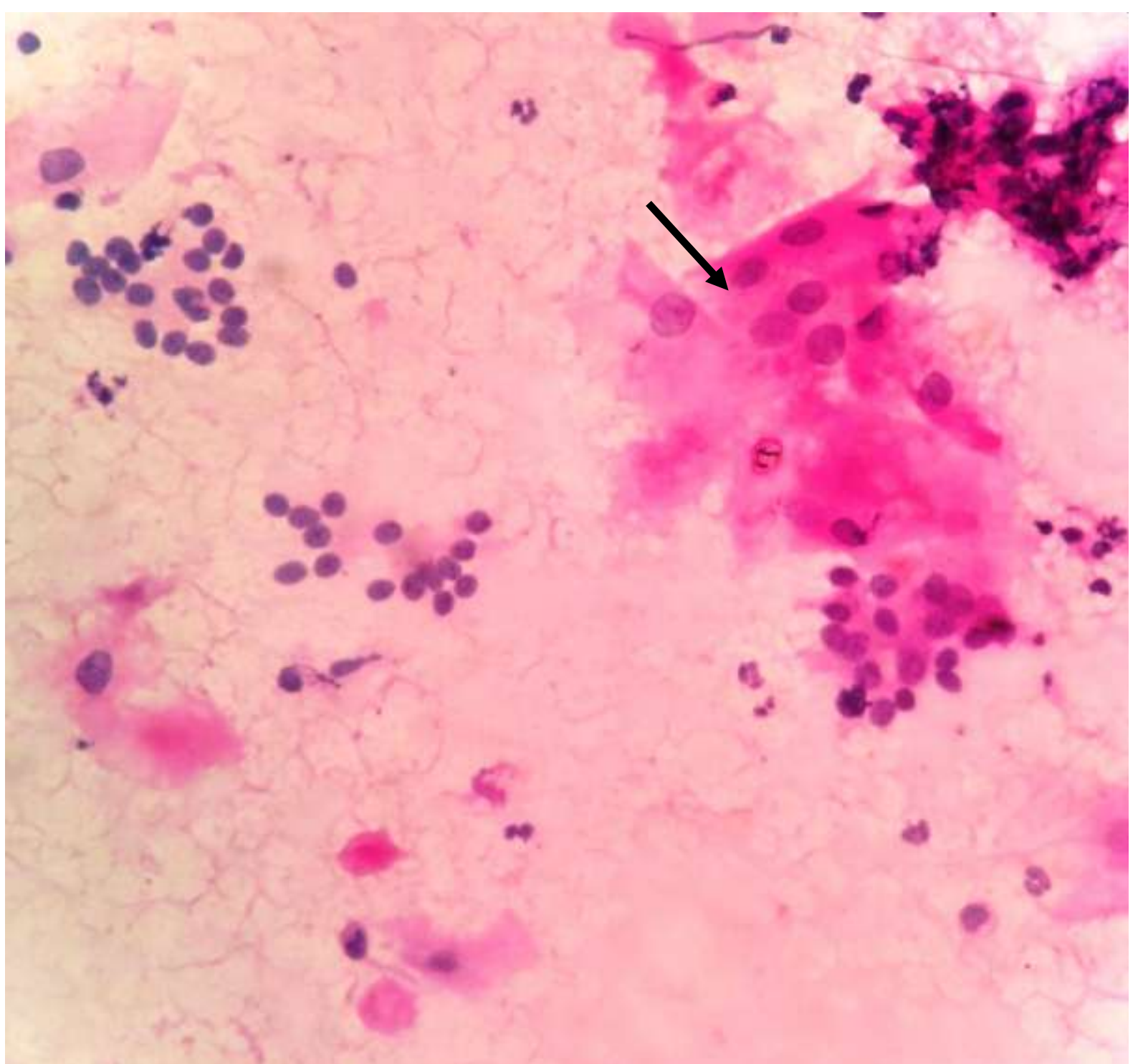

Fig 7:-Benign appearing thyroid follicular epithelial cells admixed with malignant squamous epithelial cells (black arrow) - H \& E (400X). 


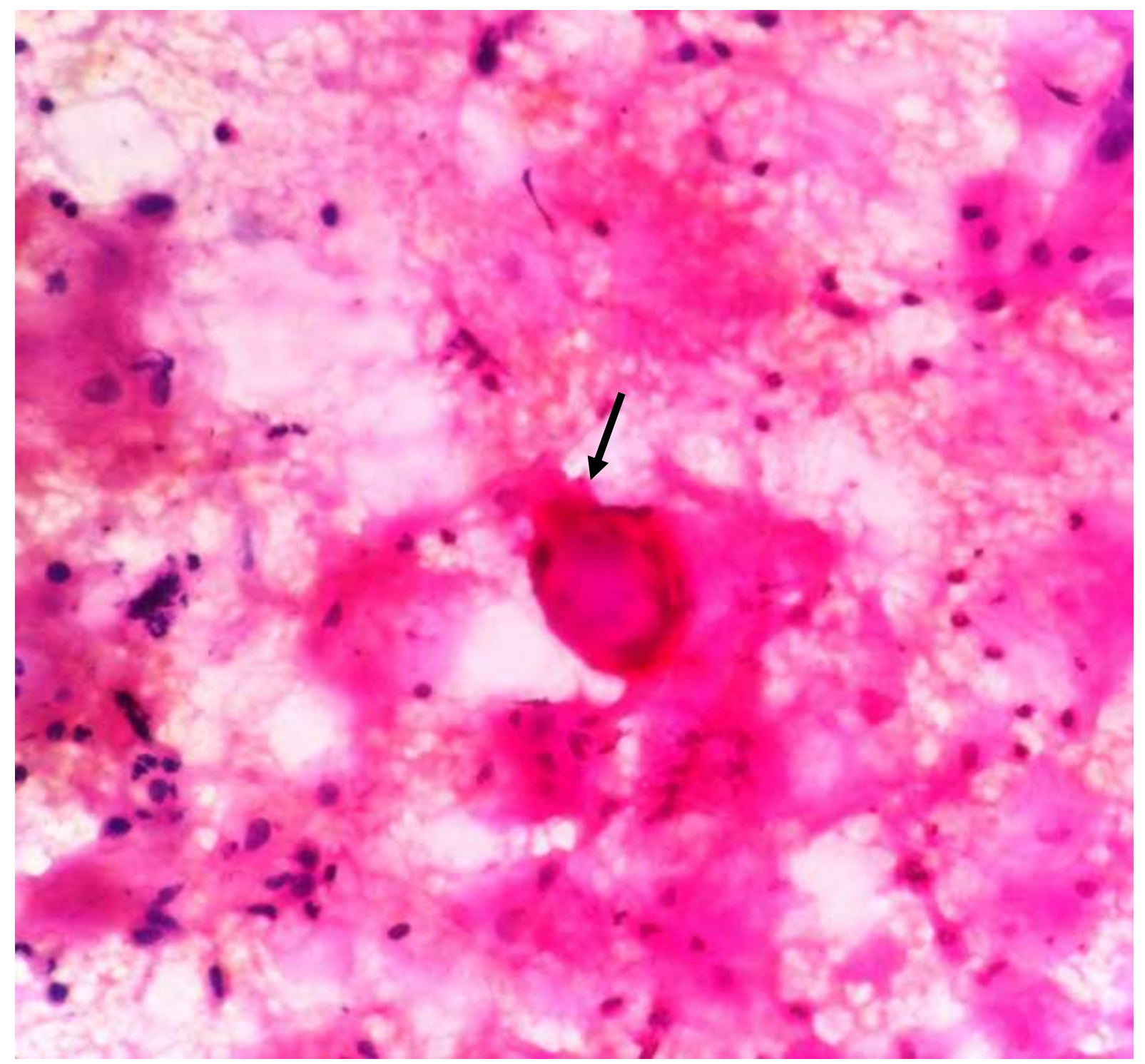

Fig 8:-Dysplastic and malignant squames with keratin pearl formation (black arrow) - H \& E (400X). 


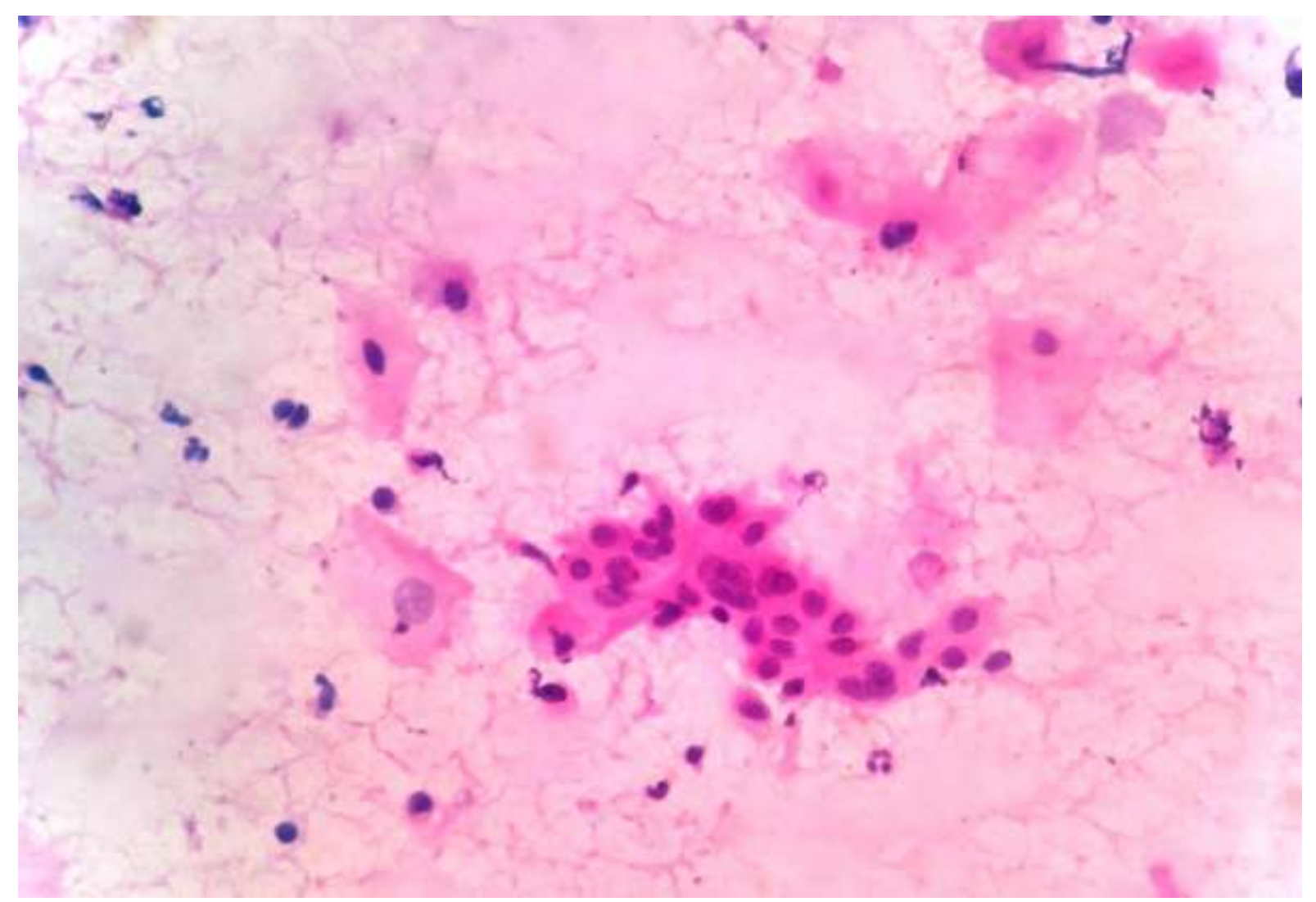

Fig 9:-Malignant squamous epithelial cells- H \& E (400X). 


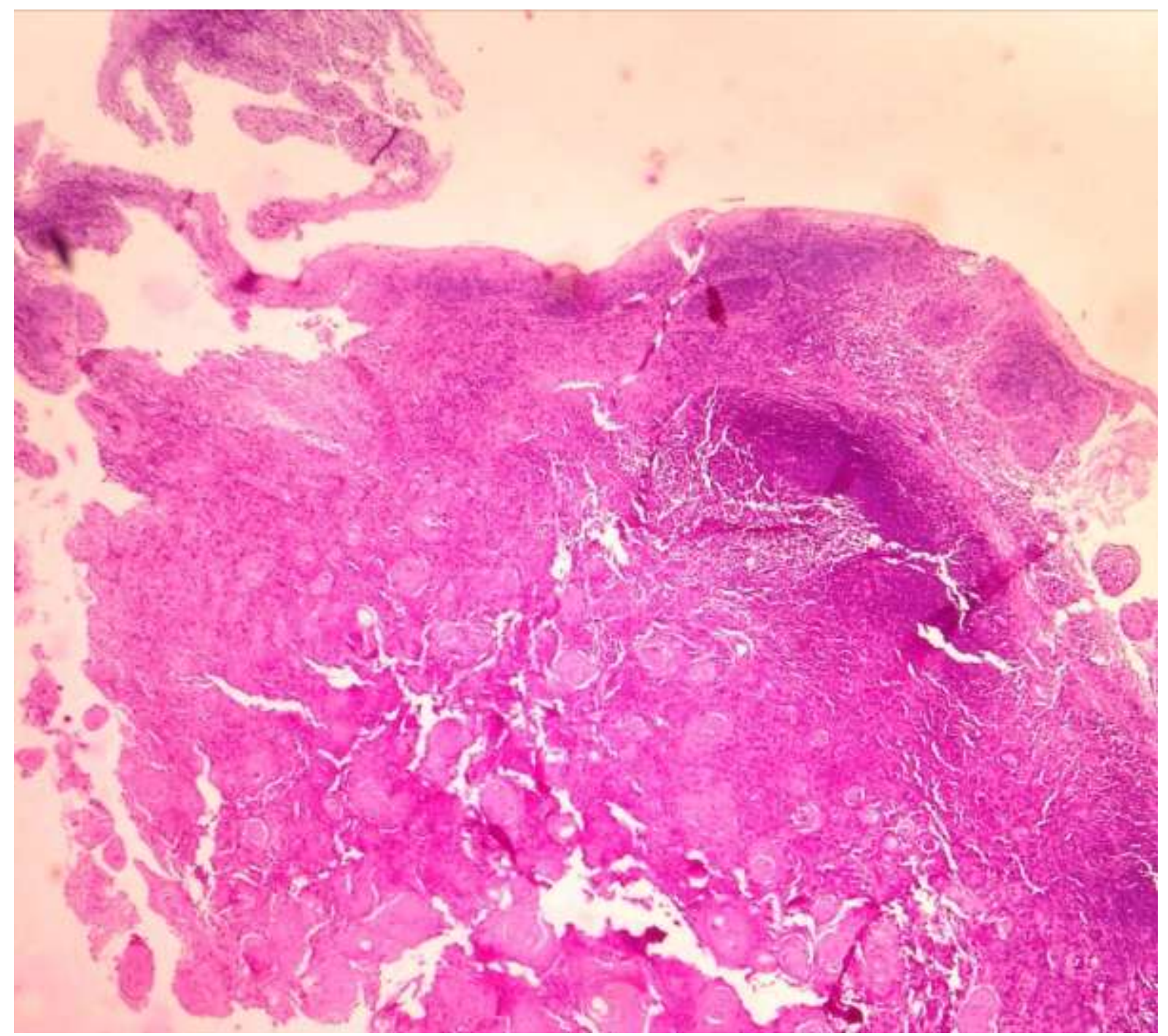

Fig 10:-Biopsy from hypopharyngeal growth showing malignant squamous epithelial cells with keratin pearl formation- H \& E (40X) 


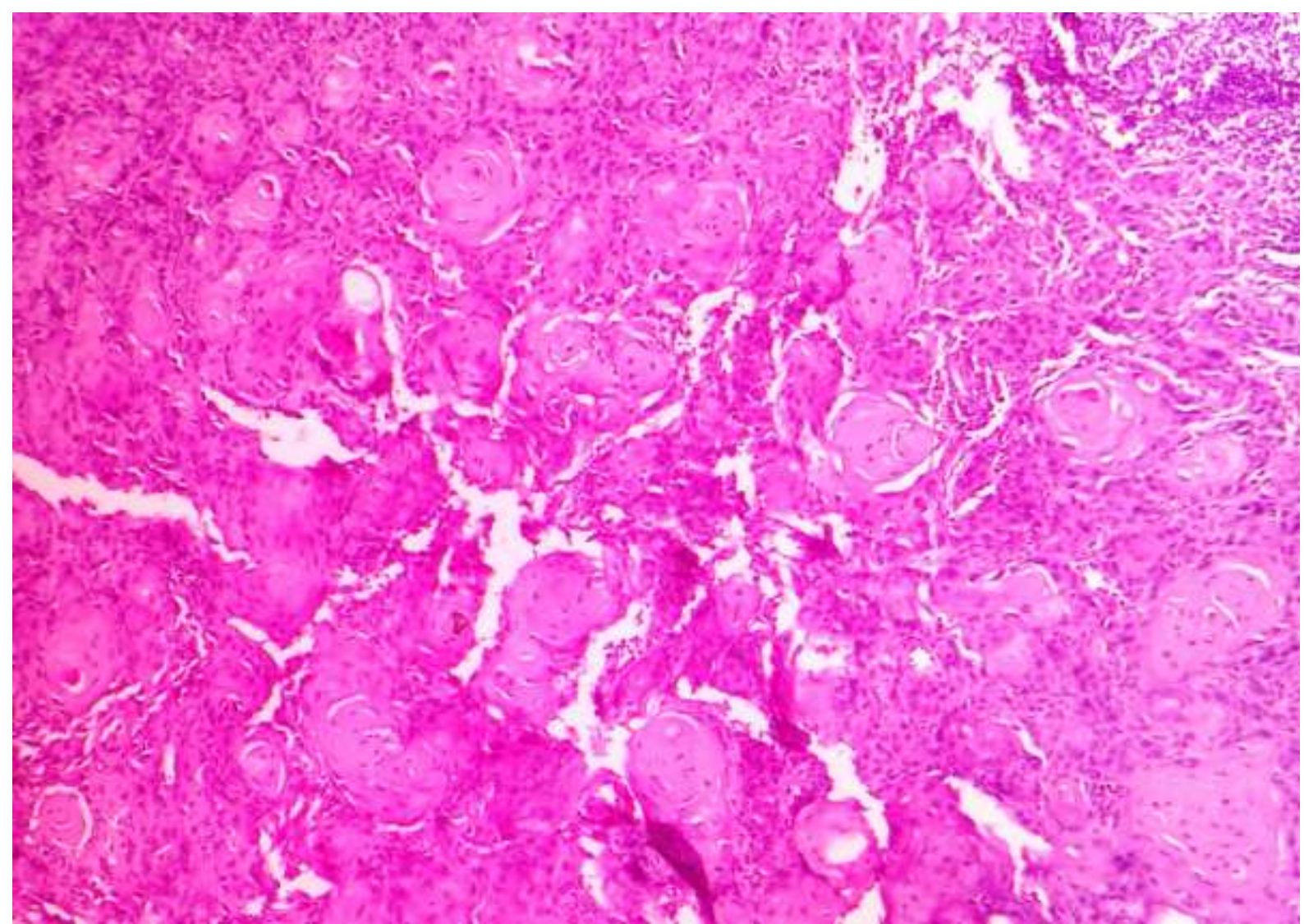

Fig 11:-Malignant squamous epithelial cells with keratin pearls- H \& E (400X)

\section{Discussion:-}

The exact incidence of secondary tumors of the thyroid is not clear, because it is not often examined or routinely investigated by imaging, during a metastatic workup. Malignancies metastasizing to the thyroid portend a dismal prognosis.

Secondary thyroid tumors account for $0.1 \%$ of all thyroid nodular lesions investigated by fine needle aspiration cytology ${ }^{(5)}$.

Secondary thyroid cancers may occur as a result of direct extension from nearby structures or metastasis via the blood stream from distant sites. Direct invasion from esophagus and head \& neck tumors are far more common than hematogenous spread. The plausible reasons for rare hematogenous spread are abundant blood flow which hinders the seeding of tumor cells, hyperoxic environment and high iodine content which inhibit the development of metastatic tumor cells ${ }^{(6)}$.

The most common primaries that metastasize to thyroid include kidney (33\%), lung (16\%), breast (16\%), esophagus $(9 \%)$ and uterus $(7 \%)^{(2)}$. Isolated case reports depicts a wide variety of other primary sites including pancreas, liver, bile duct, prostate, ovary, adrenal and parotid have been reported in the literature ${ }^{(7)}$.

The mean time interval between initial cancer diagnosis and metastasis to thyroid is 8.8 years for kidney, 10.9 years for breast and 11 years for uterus.

Metastasis to the thyroid is more commonly an autopsy diagnosis but in some cases it could be detected clinically. The patient might present with diffuse swelling of the thyroid or a nodule, dysphagia, dyspnea, dysphonia and cough (8). 
Metastatic tumors to the thyroid can easily mimic as primary thyroid cancers. Thus, it has to be differentiated from primary thyroid tumors. A detailed clinical history, radiological imaging and histopathological correlation are necessary in arriving at an accurate diagnosis. The diagnosis provided by fine needle aspiration cytology is similar to that of histopathology in diagnosing secondary tumors of the thyroid.

Some cytologic pointers indicating towards secondary malignancy are the presence of keratin, mucin, melanin and bile admixed with benign appearing thyroid follicular epithelial cells and malignant cells that are not relative to the parent organ. Ancillary techniques have to be performed in equivocal cases and this helps in identifying the metastatic lesions.

\section{Conclusion:-}

Secondary tumors of the thyroid are uncommon, but can create a diagnostic dilemma to the pathologist. Thus, in any patient with a previous history of malignancy, no matter how remote that history is, a new thyroid lesion should be considered as a metastatic deposit until proved otherwise.

\section{References:-}

1. Khandelia BK, Chakraborti S, Rai S, Kini H. Metastatic lesions to thyroid associated with dual primaries: A report of two cases. Thyroid Res Pract. 2013;10:111-3.

2. Karapanagiotou E, Saif MW, Rondoyianni D, Markaki S, Alamara C, Kiagia M, et al. Metastatic cervical carcinoma to the thyroid gland: A case report and review of the literature. Yale J Biol Med. 2006;79:165-8.

3. La Rosa S, Imperatori A, Giovanella L, Garancini S, Capella C. Thyroid metastases from typical carcinoid of the lung differentiating between medullary thyroid carcinoma and neuroendocrine tumor metastasis to the thyroid. Thyroid. 2009;19:521-6.

4. Rosa M, Toronczyk K. Fine needle aspiration biopsy of three cases of squamous cell carcinoma presenting as a thyroid mass: Cytological findings and differential diagnosis. Cytopathology. 2012;23:45-9.

5. Schmid KW, Hittmair A, Ofner C, Tötsch M, Ladurner D. Metastatic tumors in fine needle aspiration biopsy of the thyroid. ActaCytol. 1991;35:722-4.

6. Fujita T, Ogasawara Y, Doihara H, Shimizu N. Rectal adenocarcinoma metastatic to the thyroid gland. Int J ClinOncol. 2004;9:515-9.

7. Michelow PM, Leiman G. Metastases to the thyroid gland: Diagnosis by aspiration cytology. DiagnCytopathol. 1995;13:209-13.

8. Chung AY, Tran TB, Brumund KT, Weisman RA, Bouvet M. Metastases to the thyroid: A review of the literature from the last decade. Thyroid. 2012;22:258-68. 